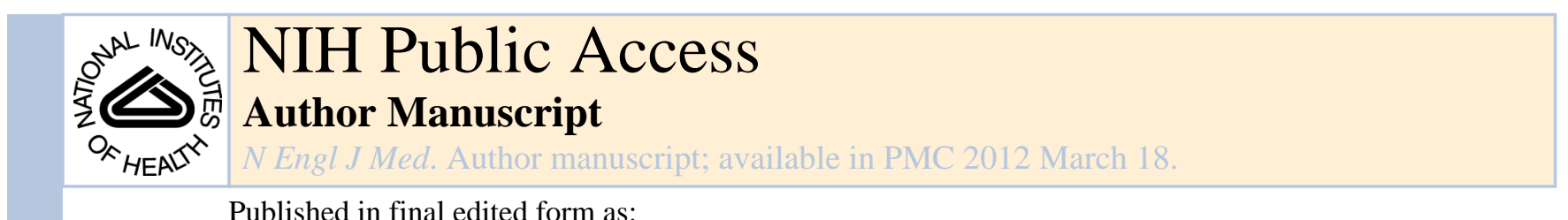

Published in final edited form as:

N Engl J Med. 2010 June 10; 362(23): 2202-2211. doi:10.1056/NEJMra0804577.

\title{
Recent Advances in Neuroblastoma
}

John M. Maris, M.D.

Center for Childhood Cancer Research, Children's Hospital of Philadelphia, University of Pennsylvania School of Medicine, and Abramson Family Cancer Research Institute - all in Philadelphia

Neuroblastoma is an embryonal tumor of the autonomic nervous system, meaning that the cell of origin is thought to be a developing and incompletely committed precursor cell derived from neural-crest tissues. ${ }^{1}$ As may be expected with a disease of developing tissues, neuroblastomas generally occur in very young children; the median age at diagnosis is 17 months. $^{2}$ The tumors arise in tissues of the sympathetic nervous system, typically in the adrenal medulla or paraspinal ganglia, and thus can present as mass lesions in the neck, chest, abdomen, or pelvis. The clinical presentation is highly variable, ranging from a mass that causes no symptoms to a primary tumor that causes critical illness as a result of local invasion, widely disseminated disease, or both. The incidence of neuroblastoma is $\mathbf{1 0 . 2}$ cases per million children under 15 years of age; it is the most common cancer diagnosed during the first year of life. ${ }^{3}$

For over a century, researchers have noted that neuroblastomas exhibit diverse and often dramatic clinical behaviors (Fig. 1). (For a timeline of the major advances in neuroblastoma research, see the Supplementary Appendix, available with the full text of this article at NEJM.org.) On the one hand, neuroblastoma accounts for disproportionate morbidity and mortality among the cancers of childhood; on the other hand, it is associated with one of the highest proportions of spontaneous and complete regression of all human cancers. ${ }^{4-6}$ Outcomes in patients with neuroblastoma have improved, with 5-year survival rates increasing from 52\% during the period from 1975 through 1977 to $74 \%$ during the period from 1999 through 2005, according to the Surveillance, Epidemiology, and End Results databases (www.seer.cancer.gov). This improvement, however, is attributable mainly to increased cure rates among patients with the more benign form of the disease; the rates among children with high-risk neuroblastoma have shown only modest improvement, despite dramatic escalations in the intensity of therapy provided. ${ }^{7}$

\section{GENETIC CAUSES}

Neuroblastoma may be considered a malignant manifestation of aberrant sympathetic nervous system development. Until recently, however, little was known about the genetic basis of this disease. As has been shown for many human cancers, a subgroup of cases display autosomal dominant inheritance. ${ }^{8}$ Mossé and colleagues recently reported that activating mutations in the tyrosine kinase domain of the ana-plastic lymphoma kinase

Copyright @ 2010 Massachusetts Medical Society.

Address reprint requests to Dr. Maris at the Children's Hospital of Philadelphia, Division of Oncology, Colket Translational Research Bldg., Rm. 3060, 3501 Civic Center Blvd., Philadelphia, PA 19104-4318 or at maris@ chop.edu.

Dr. Maris reports receiving grants from GlaxoSmithKline and Merck and being a named investigator on two pending U.S. patents for methods to identify neuroblastomas, for which he has not received royalties. No other potential conflict of interest relevant to this article was reported.

This article is dedicated to Dr. Audrey Evans, who continues to provide inspiration for all pediatric oncologists. I thank Ms. Angela Knott for assistance with earlier versions of the figures. 
$(A L K)$ oncogene account for most cases of hereditary neuroblastoma. ${ }^{9}$ These germline mutations encode for single-base substitutions in key regions of the kinase domain and result in constitutive activation of the kinase and a premalignant state. Mutations resulting in oncogene activation are also somatically acquired in 5 to $15 \%$ of neuroblastomas. ${ }^{9-12}$ Children with either sporadic or familial neuroblastoma in conjunction with congenital central hypoventilation syndrome, Hirschsprung's disease, or both usually have loss-offunction mutations in the homeobox gene $P H O X 2 B .{ }^{13,14}$ Thus, genetic testing for mutations in $A L K$ and $P H O X 2 B$ should be considered whenever a patient has a family history of neuroblastoma or has other clinical conditions that are strongly suggestive of a highly penetrant transmissible mutation, such as bilateral primary tumors of the adrenal glands. Such testing is currently available to practitioners (www.ncbi.nlm.nih.gov/sites/GeneTests). Although $A L K$ and PHOX2B mutations account for the majority of familial cases of neuroblastoma, additional familial genes may still be discovered.

In sporadic neuroblastoma cases, malignant transformation probably arises from the interaction of common DNA variants in which each individual variation has a relatively modest effect on susceptibility. A genomewide association study of neuroblastoma is currently under way, under the auspices of the Children's Oncology Group (COG). To date, the study has shown that alleles with common single-nucleotide-polymorphism variations within the putative genes FLJ22536 at chromosome band 6p22.3 and BARD1 (BRCA1associated RING domain 1) at 2q35 are significantly enriched among patients in whom neuroblastoma has developed as compared with controls. ${ }^{15,16}$ In addition, the study has also shown that a relatively common copy-number variation at $1 \mathrm{q} 21$ is associated with the development of neuroblastoma. ${ }^{17}$ Taken together, these observations suggest that this developmental childhood cancer is influenced by common DNA variations, facilitating the development of a putative genetic model for this disease (Fig. 2).

\section{DEFINING PATIENT SUBGROUPS}

There have been substantial efforts to develop a risk-classification algorithm for patients with newly diagnosed neuroblastoma. Most cooperative groups use a system that combines the assessment of easily measured clinical variables, such as the patient's age and the tumor stage, with specific biologic variables. The age at diagnosis is considered a surrogate for underlying biologic characteristics, in that younger patients are more likely to have tumors with biologic features that are associated with a benign clinical course. Although age is a continuous variable in terms of prognostication, it has been customary for clinical purposes to use a cutoff point of 12 or 18 months of age. ${ }^{2}$ The stage of the disease, as formulated in the International Neuroblastoma Staging System, ${ }^{18}$ can also be considered a surrogate marker of the tumor burden and underlying tumor biology.

At the extreme ends of the spectrum with respect to age and stage of disease, there is little controversy concerning risk classification. Older children with stage 4 (metastatic) disease are at high risk for death from refractory disease. In contrast, infants with localized tumors are almost always cured, often without cytotoxic therapy. For patients who fall between these extremes, however, it has been difficult to reach a consensus, owing to both the relative rarity of the condition and the evolving nature of molecular diagnostics. To address this issue of classification, Cohn and Pearson led a large international consortium that pooled data to develop a cohort of 8800 patients with neuroblastoma who were enrolled in research studies conducted between 1990 and 2002 in North America and Australia (COG), in Europe (International Society of Paediatric Oncology Neuroblastoma Research Network [SIOPEN-R-NET]), in Germany (Gesellschaft für Pädiatrische Onkologie und Hämatologie [GPOH]), and in Japan (Japan Advanced Neuroblastoma Study Group [JANB] and Japanese Infantile Neuroblastoma Cooperative Study Group [JINCS]). ${ }^{19}$ Analyses of this unique data 
set led to the development of a new tumor staging system that divides localized tumors into two groups on the basis of the presence or absence of rigorously defined surgical risk factors. ${ }^{20,21}$ An age cutoff point of 18 months was proposed on the basis of a review of outcomes in this extensive data set. A new International Neuroblastoma Risk Group (INRG) classification system with a total of 16 statistically distinct risk groups is based on the assessment of 13 potential prognostic factors. Four broad categories - very low risk, low risk, intermediate risk, and high risk - were proposed in terms of 5-year event-free survival rates of $>85 \%,>75$ to $\leq 85 \%, \geq 50$ to $\leq 75 \%$, and $<50 \%$, respectively, on the basis of the analysis of age at diagnosis, INRG tumor stage, histologic category, grade of tumor differentiation, DNA ploidy, and copy-number status at the $M Y C N$ oncogene locus and at chromosome 11q. The prospective implementation of this system by cooperative pediatric clinical trial groups should help to validate the system and allow the results of ongoing and future clinical trials worldwide to be compared.

Despite the advances made by the INRG committee, there is broad awareness that the clinical and pathological factors used in the INRG system are simply surrogates for underlying tumor biology. Thus, future risk-stratification efforts will probably rely more heavily on the assessment of tumor biology, which is becoming better understood. Tumorderived genomic information has been used since the 1980s to predict the course of newly diagnosed neuroblastomas, with the discovery that the $M Y C N$ oncogene is the target of the extremely high-level amplifications at chromosome band 2p24 observed in about $20 \%$ of neuroblastoma cases. Because $M Y C N$ amplification has a profound effect on the clinical outcome, it is routinely used as a biomarker for treatment stratification. ${ }^{22-24}$ Since the initial discovery of $M Y C N$, many prognostic biomarkers have been proposed for neuroblastoma, the most intensely studied of which include histopathological classification, the tumor-cell DNA index (ploidy), and specific recurrent segmental chromosomal aberrations. More recently, microarray-based technologies have permitted the detailed dissection of the neuroblastoma genome and transcriptome, and several outstanding studies indicate that patterns of DNA-based or RNA-based aberrations have substantial predictive power. ${ }^{25-30}$

Taken together, the available data suggest that DNA copy-number aberrations fall into two broad prognostic categories: whole-chromosome gains that result in hyperdiploidy and are associated with a favorable prognosis and segmental chromosomal aberrations, such as amplification of $M Y C N$ and regional loss or gain of chromosomal material, that tend to be associated with a worse outcome (Fig. 3). ${ }^{30}$ Although whole-chromosome duplication events with no segmental aberrations are strongly predictive of a favorable outcome, there is wide phenotypic variability among cases involving segmental aberrations. It is possible that yet-to-be-discovered mutations, RNA-based signatures, epigenetic alterations, or a combination of these factors will provide a basis for subdividing the higher-risk group of patients. Current work is focused on defining and validating the optimal gene set for RNA copy-number analysis; keeping this set on the order of dozens to hundreds may allow approaches based on polymerase-chain-reaction assays that can be carried out with the use of small amounts of RNA. This small scale is important because tumor-biopsy samples often contain only microgram-size quantities of tissue. In addition, current collaborative work may uncover mutations or epigenetic alterations that result in specific RNA-expression patterns, and these might be more precise in terms of risk prediction. The ultimate goal is to more precisely assign patients to appropriate treatment with the use of an approach based on molecular genetics.

\section{TREATMENT}

The biologic heterogeneity of neuroblastic tumors that occur during childhood has resulted in a dichotomization in therapeutic strategies. For tumors that have favorable biologic 
features, the clear trend has been to reduce therapeutic intensity. In contrast, the approach to tumors with adverse prognostic features has shifted over the past two decades toward intensifying chemoradiotherapy. Recently, research groups have been attempting to design therapies that will exploit the key oncogenic features found in the tumor cells, in the tumor microenvironment, or both. Table 1 outlines a general diagnostic and therapeutic approach to the major types of neuroblastoma; the remainder of this section focuses on the treatment of patients with high-risk disease.

Current treatment for high-risk neuroblastomas can be divided into three distinct phases: induction of remission, consolidation of the remission, and finally a maintenance phase focused on the eradication of minimal residual disease. Available data indicate that increasing the intensity of induction chemotherapy is associated with improvements in response rates and overall survival rates. ${ }^{34}$ One randomized, controlled trial showed that an increase in dose intensity improves the outcome. ${ }^{35}$ The backbone of the most commonly used induction chemotherapeutic regimen (developed at the Memorial Sloan-Kettering Cancer Center) includes dose-intensive cycles of cisplatin and etoposide alternating with vincristine, doxorubicin, and cyclophosphamide. ${ }^{36}$ Recently, COG investigators added topotecan to this induction regimen on the basis of data showing antineuroblastoma activity in cases of relapse. ${ }^{37-40}$ The level of response at the end of the induction phase is highly correlated with the outcome $\mathrm{e}^{41-43}$; current research is focusing on measures to induce remission at a molecular level with the use of neuroblastoma-specific gene transcripts that can reliably identify rare residual cancer cells. ${ }^{44} \mathrm{~A}$ clear and critical goal is the development of a reliable method for quantifying the tumor burden in patients with neuroblastoma. Since the presence of residual cancer cells in the hematopoietic compartment is the most likely explanation for treatment failure, methods to purify and isolate rare circulating tumor cells, or the nucleic acids from such cells, by means of a variety of immune-based capture techniques and detection of unique transcripts or cell-surface markers may lead to a greater understanding of how to handle residual tumor cells.

Since most high-risk neuroblastomas initially respond to therapy but ultimately relapse, it is likely that acquired drug resistance, the selection of rare resistant clones from a heterogeneous tumor environment, or both present major obstacles to cure. Neuroblastoma is unique among human solid tumors in that randomized clinical trials have shown an improvement in disease-free survival with myeloablative chemotherapy administered after induction therapy and followed rapidly by rescue with autologous hematopoietic progenitor cells. ${ }^{45-47}$ The optimal chemotherapeutic regimen for myeloablation is not known, although data indicate that rapid, sequential, tandem myeloablative consolidation therapy may improve the outcome. ${ }^{48}$ Such an approach is currently being tested in a randomized phase 3 trial. Although most cooperative groups consider myeloablative consolidation part of the standard management of high-risk neuroblastoma, postremission consolidation approaches are needed that can more precisely circumvent the molecular mechanisms of acquired drug resistance.

Classic experiments from the 1980s have shown that neuroblastoma cell lines can often be induced to terminally differentiate on exposure to retinoid compounds. ${ }^{49,50}$ These observations led to a randomized clinical trial in which isotretinoin (13-cis-retinoic acid) was used after myeloablative consolidation therapy in patients with neuroblastoma; the risk of relapse was reduced among those who received isotretinoin. ${ }^{46}$ Although isotretinoin is now part of standard therapy during the first remission in patients with high-risk neuroblastoma, there are still many unanswered questions about proper dosing, intraindividual and interindividual variation in pharmacokinetic features, and the frequency of potential long-term toxicities. 
Neuroblastoma cells almost uniformly express the disialoganglioside GD2 on their surfaces, providing a tractable target for passive immunotherapeutic approaches ${ }^{51-53}$ For example, the murine monoclonal antibody $3 \mathrm{~F} 8$ has been shown to have activity against neuroblastoma, especially in clearing the bone marrow of metastatic disease, but 3F8 has never been tested in a randomized, controlled trial. ${ }^{54,55}$ The chimeric anti-GD2 monoclonal antibody ch14.18 has been shown to have some antitumor activity in preclinical models, and some evidence suggests that this activity may be enhanced by the coadministration of interleukin-2 or granulocyte-macrophage colony-stimulating factor (GM-CSF) in alternating cycles through antibody-dependent cellular cytotoxicity. ${ }^{56-58} \mathrm{Yu}$ and colleagues in the COG recently completed a randomized phase 3 clinical trial of an intensive immunotherapeutic regimen using ch14.18 alternating with cycles of GM-CSF or interleukin-2 added to a regimen of isotretinoin. ${ }^{59}$ The results showed a dramatic improvement in 2-year event-free survival in the immunotherapy group (66\%, vs. $46 \%$ for the subjects who received isotretinoin alone). The study by $\mathrm{Yu}$ et al. is unique in that it showed a survival advantage for an antibody that targets a glycolipid and also included therapy that presumably enhances antibody-dependent cellular cytotoxicity by means of combination therapy with cytokines. In contrast, an uncontrolled trial showed no benefit with ch14.18 alone, ${ }^{60}$ suggesting that passive immunotherapy may require cytokine-mediated activation of the effector arm of the immune system in patients with neuroblastoma, although other explanations for the discrepant results are possible.

\section{REFR ACTORY HIGH-RISK NEUROBLASTOMA}

Despite recent advances, 50 to $60 \%$ of patients with high-risk neuroblastoma have a relapse, and to date there are no salvage treatment regimens known to be curative. Over the past decade, however, several highly active agents have been identified that may help such patients, and it appears likely that these treatments are increasing the number of patients whose survival is prolonged. In contrast to the approach at the time of the initial diagnosis, when the focus is to provide intensive therapy within as short a time as feasible, the approach to relapse needs to focus on neuroblastoma as a chronic disease that can often be managed for years. The issue of survival after relapse is a delicate one for clinicians who treat patients with neuroblastoma; it is necessary to offer hope for a cure but also to acknowledge that, at least until recently, long-term disease-free survival after a relapse was rarely seen, if ever. The hope lies in the possibility that recent advances in our understanding of the molecular basis of high-risk neuroblastoma have identified tractable therapeutic targets that may respond to novel agents with unprecedented antitumor activity when studied in the clinical setting.

\section{DEVELOPMENT OF NEW DRUGS AND FUTURE DIRECTIONS}

An extensive literature and efforts by many groups have been directed toward the development of new drugs to treat high-risk neuroblastoma. There has been a move away from the empirical testing of agents that may or may not have activity against adult human cancers to a more pragmatic approach, in which only those compounds for which there is a strong preclinical rationale are being tested in patients. This section highlights some, but certainly not all, recent advances in therapies for patients with neuroblastoma.

The successful use of treatment with the anti-GD2 monoclonal antibody to prevent relapse in patients with neuroblastoma is an example of an immunotherapeutic approach to the eradication of residual neuroblastoma cells at the completion of cytotoxic therapy. ${ }^{56}$ Future efforts will be focused on improving antibody-based approaches, as well as on developing synergistic combination therapies. There are plans to study the humanized anti-GD2 immunocytokine that is engineered to target the delivery of interleukin-2 (hu14.18- 
interleukin-2) to the tumor microenvironment. This treatment appears to have substantial but manageable toxicity, ${ }^{61}$ and in a recent phase 2 study, it showed antitumor activity in patients with a relatively small disease burden. ${ }^{62}$ In addition, the previously described regimen reported by $\mathrm{Yu}$ and colleagues also includes isotretinoin (13-cis retinoic acid), ${ }^{59}$ and there is interest in the possibility of improving the retinoid component of therapy for patients with minimal residual disease. Fenretinide, a synthetic retinoid that exerts antitumor activity in neuroblastoma models primarily through the induction of programmed cell death, has been proposed as an alternative or additional retinoid to be used to target rare residual neuroblastoma cells that survive after intensive chemoradiotherapy ${ }^{63,64}$ Finally, since the immunotherapeutic approaches currently used by the COG have significant immediate toxicity, efforts in Europe to combine anti-GD2 antibody therapy with lower doses of interleukin- 2 could possibly lead to the development of safer methods for eradicating minimal residual disease.

Because neuroblastomas arise from the developing sympathetic nervous system, the majority of these tumors express the norepinephrine transporter on their cell surface. This fact was exploited decades ago when radiolabeling of the norepinephrine analogue metaiodobenzylguanidine ( ${ }^{131}$ I-labeled or ${ }^{123}$ I-labeled MIBG) was used to develop a scintigraphic localization method for detecting tumors that express these transporters, such as neuroblastomas. Investigators have subsequently taken advantage of this molecular target to deliver high levels of radiation to neuroblastoma cells, despite the fact that norepinephrine transporters are not actively involved in the oncogenic process. ${ }^{131}$ I-labeled MIBG has been extensively investigated as a potential therapeutic agent ${ }^{65}$ and has the highest objective response rate of any drug studied in patients with relapse. ${ }^{66}$ Current efforts are focused on integrating targeted radiotherapy with ${ }^{131}$ I-labeled MIBG into the consolidation phase of therapy, an approach that appears to be feasible in light of the results of a phase 1 study in which this agent showed promising antitumor activity in patients with primary refractory disease. ${ }^{67}$ One of the potential theoretical problems with ${ }^{131}$ I-based therapy is that the DNA damage occurs at a relatively long path length from the $\beta$-particle emission of the compound. Thus, a cell that takes up ${ }^{131}$ I-labeled MIBG is not killed; to achieve sufficient overall cytotoxicity, the DNA-damaging energy must travel to adjacent cells. Since isolated residual tumor cells exist primarily in the marrow compartment, drugs radiolabeled with $\alpha$ emitting radionuclides, which have much greater energy and shorter path lengths than do $\beta$ emitting radionuclides, might have superior efficacy. ${ }^{68}$

Two large collaborative research efforts are now focused on discovering additional therapeutic targets for neuroblastoma and other pediatric cancers. The Therapeutically Applicable Research to Generate Effective Treatments (TARGET) program (http://target.cancer.gov) is being conducted in close alignment with the Cancer Genome Atlas project. As the acronym suggests, the genomic profiling and resequencing efforts are focused not only on discovering the mechanisms that drive oncogenesis, but also on identifying compounds that will be likely to work specifically on the identified pathways. In addition, the Pediatric Preclinical Testing Program (PPTP) is using murine models of pediatric cancers to screen drugs that are in the early stages of clinical development for use in the treatment of more common adult cancers for possible activity against pediatric diseases. So far this program has screened almost three dozen anticancer agents; for neuroblastoma, one of the most compelling results to date was the broad activity of an inhibitor against aurora kinase A, the key regulator of the cell-cycle G2-M checkpoint. ${ }^{69}$ This drug was fast-tracked to a pediatric phase 1 trial on the basis of these results; if antineuroblastoma activity is confirmed in the clinical setting, the power of this screening approach will be confirmed, since there were no a priori data recommending aurora kinase A as a potential molecular target. The TARGET and PPTP approaches are complementary, and 
both can inform and provide prioritization for the critical experiments that are in the early phase of clinical testing in patients with refractory neuroblastoma.

The discovery of $A L K$ as the major neuroblastoma-predisposition gene was immediately extended to show that $A L K$ somatic mutation or gene amplification occurs in up to $15 \%$ of newly diagnosed neuroblastomas. ${ }^{9-12}$ The fact that neuroblastoma-derived cell lines show a much higher frequency of mutation (30\%) suggests that mutations may be acquired or selected for, since the majority of cell lines are derived from patients at the time of relapse. Accumulating preclinical data show that targeted inhibition of ALK in cell models that harbor $A L K$ mutation or amplification is highly effective, and these observations are providing the basis for early-phase clinical trials. ${ }^{70}$ If ALK inhibition is restricted to tumors with aberrant ALK signaling, ethical methods of obtaining access to tumor cells will need to be developed so that patients can be appropriately selected for ALK-inhibition-based therapies.

The future holds promise for making considerable advances in our understanding and treatment of neuroblastoma. From the basic-science perspective, it is likely that the majority of critical mutations that cause neuroblastoma or influence its natural history will be discovered. This work should identify the key molecular targets for rational drug development. The rich history of international collaboration in studying this disease will afford the opportunity to test these new approaches in carefully controlled clinical trials that should result in more precise and effective therapeutic strategies. In the meantime, survivors of high-risk neuroblastoma require ongoing multi-disciplinary follow-up to reduce the longterm morbidity that often accompanies cure with the therapy currently provided.

\section{Supplementary Material}

Refer to Web version on PubMed Central for supplementary material.

\section{Acknowledgments}

Supported by the Giulio D'Angio Endowed Chair in Neuroblastoma Research at the Children's Hospital of Philadelphia.

\section{References}

1. Hoehner JC, Gestblom C, Hedborg F, Sandstedt B, Olsen L, Pahlman S. A developmental model of neuroblastoma: differentiating stroma-poor tumors' progress along an extra-adrenal chromaffin lineage. Lab Invest. 1996; 75:659-75. [PubMed: 8941212]

2. London WB, Castleberry RP, Matthay KK, et al. Evidence for an age cutoff greater than 365 days for neuroblastoma risk group stratification in the Children's Oncology Group. J Clin Oncol. 2005; 23:6459-65. [PubMed: 16116153]

3. Ries, LAG.; Smith, MA.; Gurney, JG., et al. Cancer incidence and survival among children and adolescents: United States SEER program 1975-1995. Bethesda, MD: National Cancer Institute; 1999. (NIH publication no. 99-4649.)

4. Carlsen NL. How frequent is spontaneous remission of neuroblastomas? Implications for screening. Br J Cancer. 1990; 61:441-6. [PubMed: 2328213]

5. Cole WH, Everson TC. Spontaneous regression of cancer: preliminary report. Ann Surg. 1956; 144:366-83. [PubMed: 13363274]

6. Yamamoto K, Hanada R, Kikuchi A, et al. Spontaneous regression of localized neuroblastoma detected by mass screening. J Clin Oncol. 1998; 16:1265-9. [PubMed: 9552024]

7. Maris JM, Hogarty MD, Bagatell R, Cohn SL. Neuroblastoma. Lancet. 2007; 369:2106-20. [PubMed: 17586306] 
8. Knudson AG Jr, Strong LC. Mutation and cancer: neuroblastoma and pheochromocytoma. Am J Hum Genet. 1972; 24:514-32. [PubMed: 4340974]

9. Mossé YP, Laudenslager M, Longo L, et al. Identification of ALK as a major familial neuroblastoma predisposition gene. Nature. 2008; 455:930-5. [PubMed: 18724359]

10. Janoueix-Lerosey I, Lequin D, Brugières L, et al. Somatic and germline activating mutations of the ALK kinase receptor in neuroblastoma. Nature. 2008; 455:967-70. [PubMed: 18923523]

11. George RE, Sanda T, Hanna M, et al. Activating mutations in ALK provide a therapeutic target in neuroblastoma. Nature. 2008; 455:975-8. [PubMed: 18923525]

12. Chen Y, Takita J, Choi YL, et al. Oncogenic mutations of ALK kinase in neuroblastoma. Nature. 2008; 455:971-4. [PubMed: 18923524]

13. Mosse YP, Laudenslager M, Khazi D, et al. Germline PHOX2B mutation in hereditary neuroblastoma. Am J Hum Genet. 2004; 75:727-30. [PubMed: 15338462]

14. Trochet D, Bourdeaut F, Janoueix-Lerosey I, et al. Germ-line mutations of the paired-like homeobox 2B (PHOX2B) gene in neuroblastoma. Am J Hum Genet. 2004; 74:761-4. [PubMed: 15024693]

15. Capasso M, Devoto M, Hou C, et al. Common variations in BARD1 influence susceptibility to high-risk neuroblastoma. Nat Genet. 2009; 41:718-23. [PubMed: 19412175]

16. Maris JM, Mosse YP, Bradfield JP, et al. Chromosome 6p22 locus associated with clinically aggressive neuroblastoma. N Engl J Med. 2008; 358:2585-93. [PubMed: 18463370]

17. Diskin SJ, Hou C, Glessner JT, et al. Copy number variation at 1q21. 1 associated with neuroblastoma. Nature. 2009; 459:987-91. [PubMed: 19536264]

18. Brodeur GM, Pritchard J, Berthold F, et al. Revisions of the international criteria for neuroblastoma diagnosis, staging, and response to treatment. J Clin Oncol. 1993; 11:1466-77. [PubMed: 8336186]

19. Cohn SL, Pearson AD, London WB, et al. The International Neuroblastoma Risk Group (INRG) classification system: an INRG Task Force report. J Clin Oncol. 2009; 27:289-97. [PubMed: 19047291]

20. Cecchetto G, Mosseri V, De Bernardi B, et al. Surgical risk factors in primary surgery for localized neuroblastoma: the LNESG1 study of the European International Society of Pediatric Oncology Neuroblastoma Group. J Clin Oncol. 2005; 23:8483-9. [PubMed: 16293878]

21. Monclair T, Brodeur GM, Ambros PF, et al. The International Neuroblastoma Risk Group (INRG) staging system: an INRG Task Force report. J Clin Oncol. 2009; 27:298-303. [PubMed: 19047290]

22. Schwab M, Alitalo K, Klempnauer KH, et al. Amplified DNA with limited homology to myc cellular oncogene is shared by human neuroblastoma cell lines and a neuroblastoma tumour. Nature. 1983; 305:245-8. [PubMed: 6888561]

23. Brodeur GM, Seeger RC, Schwab M, Varmus HE, Bishop JM. Amplification of N-myc in untreated human neuroblastomas correlates with advanced disease stage. Science. 1984; 224:1121-4. [PubMed: 6719137]

24. Seeger RC, Brodeur GM, Sather H, et al. Association of multiple copies of the N-myc oncogene with rapid progression of neuroblastomas. N Engl J Med. 1985; 313:1111-6. [PubMed: 4047115]

25. Oberthuer A, Berthold F, Warnat P, et al. Customized oligonucleotide microarray gene expressionbased classification of neuroblastoma patients outperforms current clinical risk stratification. J Clin Oncol. 2006; 24:5070-8. [PubMed: 17075126]

26. Asgharzadeh S, Pique-Regi R, Sposto R, et al. Prognostic significance of gene expression profiles of metastatic neuroblastomas lacking MYCN gene amplification. J Natl Cancer Inst. 2006; 98:1193-203. [PubMed: 16954472]

27. Ohira M, Oba S, Nakamura Y, et al. Expression profiling using a tumor-specific cDNA microarray predicts the prognosis of intermediate risk neuroblastomas. Cancer Cell. 2005; 7:337-50. [PubMed: 15837623]

28. Wei JS, Greer BT, Westermann F, et al. Prediction of clinical outcome using gene expression profiling and artificial neural networks for patients with neuroblastoma. Cancer Res. 2004; 64:6883-91. [PubMed: 15466177] 
29. Spitz R, Oberthuer A, Zapatka M, et al. Oligonucleotide array-based comparative genomic hybridization $(\mathrm{aCGH})$ of 90 neuroblastomas reveals aberration patterns closely associated with relapse pattern and outcome. Genes Chromosomes Cancer. 2006; 45:1130-42. [PubMed: 16958102]

30. Janoueix-Lerosey I, Schleiermacher G, Michels E, et al. Overall genomic pattern is a predictor of outcome in neuroblastoma. J Clin Oncol. 2009; 27:1026-33. [PubMed: 19171713]

31. D'Angio GJ, Evans AE, Koop CE. Special pattern of widespread neuroblastoma with a favourable prognosis. Lancet. 1971; 1:1046-9. [PubMed: 4102970]

32. Matthay KK. Stage 4S neuroblastoma: what makes it special? J Clin Oncol. 1998; 16:2003-6. [PubMed: 9626196]

33. Hero B, Simon T, Spitz R, et al. Localized infant neuroblastomas often show spontaneous regression: results of the prospective trials NB95-S and NB97. J Clin Oncol. 2008; 26:1504-10. [PubMed: 18349403]

34. Cheung NV, Heller G. Chemotherapy dose intensity correlates strongly with response, median survival, and median progression-free survival in metastatic neuroblastoma. J Clin Oncol. 1991; 9:1050-8. [PubMed: 2033419]

35. Pearson AD, Pinkerton CR, Lewis IJ, Imeson J, Ellershaw C, Machin D. High-dose rapid and standard induction chemotherapy for patients aged over 1 year with stage 4 neuroblastoma: a randomised trial. Lancet Oncol. 2008; 9:247-56. [PubMed: 18308250]

36. Kushner BH, LaQuaglia MP, Bonilla MA, et al. Highly effective induction therapy for stage 4 neuroblastoma in children over 1 year of age. J Clin Oncol. 1994; 12:2607-13. [PubMed: 7527454]

37. Längler A, Christaras A, Abshagen K, Krauth K, Hero B, Berthold F. Topotecan in the treatment of refractory neuroblastoma and other malignant tumors in childhood - a phase-II study. Klin Padiatr. 2002; 214:153-6. [PubMed: 12165894]

38. Garaventa A, Luksch R, Biasotti S, et al. A phase II study of topotecan with vincristine and doxorubicin in children with recurrent/refractory neuroblastoma. Cancer. 2003; 98:2488-94. [PubMed: 14635085]

39. London WB, Frantz CN, Campbell LA, et al. Phase II randomized comparison of topotecan plus cyclophosphamide vs. to-potecan alone in children with recurrent or refractory neuroblastoma: a Children's Oncology Group study. J Clin Oncol. (in press).

40. Park JR, Stewart CF, London WB, et al. A topotecan-containing induction regimen for treatment of high risk neuroblastoma. J Clin Oncol. 2006; 24(Suppl):18S. abstract.

41. Matthay KK, Edeline V, Lumbroso J, et al. Correlation of early metastatic response by 123Imetaiodobenzylguanidine scintigraphy with overall response and event-free survival in stage IV neuroblastoma. J Clin Oncol. 2003; 21:2486-91. [PubMed: 12829667]

42. Katzenstein HM, Cohn SL, Shore RM, et al. Scintigraphic response by 123Imetaiodobenzylguanidine scan correlates with event-free survival in high-risk neuroblastoma. J Clin Oncol. 2004; 22:3909-15. [PubMed: 15459212]

43. Schmidt M, Simon T, Hero B, Schicha H, Berthold F. The prognostic impact of functional imaging with (123)I-mIBG in patients with stage 4 neuroblastoma $>1$ year of age on a high-risk treatment protocol: results of the German Neuroblastoma Trial NB97. Eur J Cancer. 2008; 44:1552-8. [PubMed: 18424129]

44. Beiske K, Burchill SA, Cheung IY, et al. Consensus criteria for sensitive detection of minimal neuroblastoma cells in bone marrow, blood and stem cell preparations by immunocytology and QRT-PCR: recommendations by the International Neuroblastoma Risk Group Task Force. Br J Cancer. 2009; 100:1627-37. [PubMed: 19401690]

45. Berthold F, Boos J, Burdach S, et al. Myeloablative megatherapy with autologous stem-cell rescue versus oral maintenance chemotherapy as consolidation treatment in patients with high-risk neuroblastoma: a randomised controlled trial. Lancet Oncol. 2005; 6:649-58. [PubMed: 16129365]

46. Matthay KK, Villablanca JG, Seeger RC, et al. Treatment of high-risk neuroblastoma with intensive chemotherapy, radiotherapy, autologous bone marrow transplantation, and 13-cisretinoic acid. N Engl J Med. 1999; 341:1165-73. [PubMed: 10519894] 
47. Pritchard J, Cotterill SJ, Germond SM, Imeson J, de Kraker J, Jones DR. High dose melphalan in the treatment of advanced neuroblastoma: results of a randomised trial (ENSG-1) by the European Neuroblastoma Study Group. Pediatr Blood Cancer. 2005; 44:348-57. [PubMed: 15546135]

48. George RE, Li S, Medeiros-Nancarrow C, et al. High-risk neuroblastoma treated with tandem autologous peripheral-blood stem cell-supported transplantation: long-term survival update. J Clin Oncol. 2006; 24:2891-6. [PubMed: 16782928]

49. Sidell N. Retinoic acid-induced growth inhibition and morphologic differentiation of human neuroblastoma cells in vitro. J Natl Cancer Inst. 1982; 68:589-96. [PubMed: 7040765]

50. Thiele CJ, Reynolds CP, Israel MA. Decreased expression of N-myc precedes retinoic acidinduced morphological differentiation of human neuroblastoma. Nature. 1985; 313:404-6. [PubMed: 3855502]

51. Schulz G, Cheresh DA, Varki NM, Yu A, Staffileno LK, Reisfeld RA. Detection of ganglioside GD2 in tumor tissues and sera of neuroblastoma patients. Cancer Res. 1984; 44:5914-20. [PubMed: 6498849]

52. Saarinen UM, Coccia PF, Gerson SL, Pelley R, Cheung NK. Eradication of neuroblastoma cells in vitro by monoclonal antibody and human complement: method for purging autologous bone marrow. Cancer Res. 1985; 45:5969-75. [PubMed: 2414004]

53. Mujoo K, Cheresh DA, Yang HM, Reisfeld RA. Disialoganglioside GD2 on human neuroblastoma cells: target antigen for monoclonal antibody-mediated cytolysis and suppression of tumor growth. Cancer Res. 1987; 47:1098-104. [PubMed: 3100030]

54. Cheung NK, Kushner BH, Yeh SDJ, Larson SM. 3F8 monoclonal antibody treatment of patients with stage 4 neuroblastoma: a phase II study. Int J Oncol. 1998; 12:1299-306. [PubMed: 9592190]

55. Cheung NK, Lazarus H, Miraldi FD, et al. Ganglioside GD2 specific monoclonal antibody 3F8: a phase I study in patients with neuroblastoma and malignant melanoma. J Clin Oncol. 1987; 5:1430-40. [PubMed: 3625258]

56. Barker E, Mueller BM, Handgretinger R, Herter M, Yu AL, Reisfeld RA. Effect of a chimeric antiganglioside GD2 antibody on cell-mediated lysis of human neuroblastoma cells. Cancer Res. 1991; 51:144-9. [PubMed: 1988079]

57. Barker E, Reisfeld RA. A mechanism for neutrophil-mediated lysis of human neuroblastoma cells. Cancer Res. 1993; 53:362-7. [PubMed: 8417829]

58. Hank JA, Robinson RR, Surfus J, et al. Augmentation of antibody dependent cell mediated cytotoxicity following in vivo therapy with recombinant interleukin 2. Cancer Res. 1990; 50:5234-9. [PubMed: 2386933]

59. Yu AL, Gilman AL, Ozkaynak MF, et al. A phase III randomized trial of the chimeric anti-GD2 antibody ch14.18 with GM-CSF and IL2 as immunotherapy following dose intensive chemotherapy for high-risk neuroblastoma: Children's Oncology Group (COG) study ANBL0032. J Clin Oncol. 2009; 27(Suppl):15S. abstract.

60. Simon T, Hero B, Faldum A, et al. Consolidation treatment with chimeric anti-GD2-antibody ch14. 18 in children older than 1 year with metastatic neuroblastoma. J Clin Oncol. 2004; 22:3549-57. [PubMed: 15337804]

61. Osenga KL, Hank JA, Albertini MR, et al. A phase I clinical trial of the hu14. 18-IL2 (EMD 273063) as a treatment for children with refractory or recurrent neuroblastoma and melanoma: a study of the Children's Oncology Group. Clin Cancer Res. 2006; 12:1750-9. [PubMed: 16551859]

62. Shusterman S, London WB, Gillies SD, et al. Anti-neuroblastoma activity of hu14.18-IL2 against minimal residual disease in a Children's Oncology Group (COG) phase II study. J Clin Oncol. 2008; 26(Suppl):3002. abstract.

63. Maurer BJ, Metelitsa LS, Seeger RC, Cabot MC, Reynolds CP. Increase of ceramide and induction of mixed apoptosis/necrosis by N-(4-hydroxyphenyl)-retinamide in neuroblastoma cell lines. $\mathrm{J}$ Natl Cancer Inst. 1999; 91:1138-46. [PubMed: 10393722]

64. Garaventa A, Luksch R, Lo Piccolo MS, et al. Phase I trial and pharmacokinetics of fenretinide in children with neuroblastoma. Clin Cancer Res. 2003; 9:2032-9. [PubMed: 12796365]

65. DuBois SG, Matthay KK. Radiolabeled metaiodobenzylguanidine for the treatment of neuroblastoma. Nucl Med Biol. 2008; 35(Suppl 1):S35-S48. [PubMed: 18707633] 
66. Matthay KK, Yanik G, Messina J, et al. Phase II study on the effect of disease sites, age, and prior therapy on response to iodine-131-metaiodobenzylguanidine therapy in refractory neuroblastoma. J Clin Oncol. 2007; 25:1054-60. [PubMed: 17369569]

67. Matthay KK, Tan JC, Villablanca JG, et al. Phase I dose escalation of iodine-131metaiodobenzylguanidine with myeloablative chemotherapy and autologous stem-cell transplantation in refractory neuroblastoma: a new approaches to Neuroblastoma Therapy Consortium Study. J Clin Oncol. 2006; 24:500-6. [PubMed: 16421427]

68. Boyd M, Mairs RJ, Keith WN, et al. An efficient targeted radiotherapy/gene therapy strategy utilising human telomerase promoters and radioastatine and harnessing radiation-mediated bystander effects. J Gene Med. 2004; 6:937-47. [PubMed: 15293352]

69. Maris JM, Morton CL, Gorlick R, et al. Initial testing of the aurora kinase A inhibitor MLN8237 by the Pediatric Preclinical Testing Program (PPTP). Pediatr Blood Cancer. 2010 January 27. (Epub ahead of print).

70. Mossé YP, Wood A, Maris JM. Inhibition of ALK signaling for cancer therapy. Clin Cancer Res. 2009; 15:5609-14. [PubMed: 19737948] 


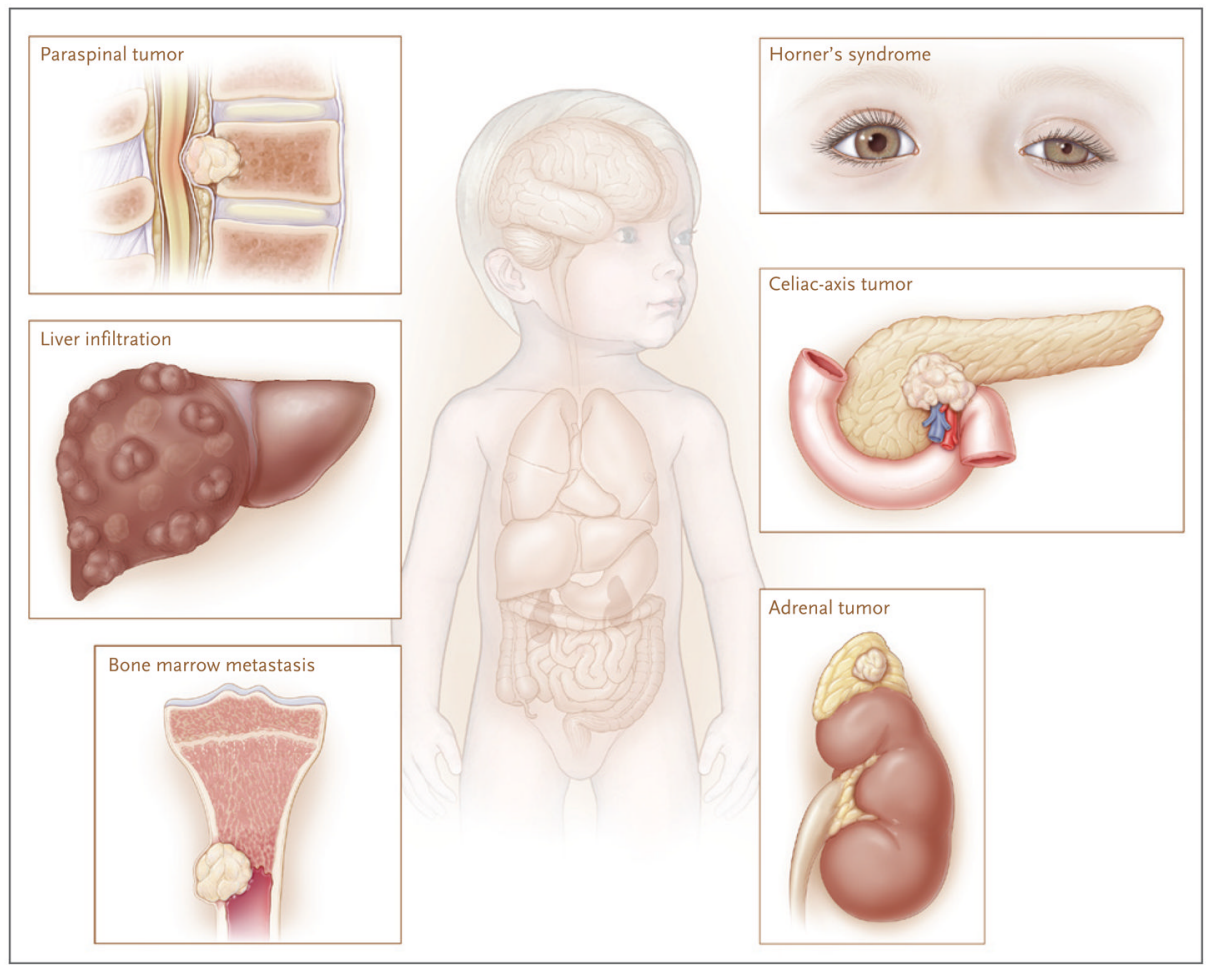

Figure 1. Clinical Presentations of Neuroblastoma

Neuroblastoma is a childhood cancer that is diagnosed at a median age of about 17 months. Tumors can arise anywhere along the sympathetic nervous system, with the majority occurring in the adrenal medulla. Primary tumors in the neck or upper chest can cause Horner's syndrome (ptosis, miosis, and anhidrosis). Tumors along the spinal column can expand through the intraforaminal spaces and cause cord compression, with resulting paralysis. Although many lower-stage neuroblastomas are encapsulated and can be surgically excised with little chance of complications, higher-stage tumors often infiltrate local organ structures, surround critical nerves and vessels such as the celiac axis, and are largely unresectable at the time of diagnosis. Neuroblastomas typically metastasize to regional lymph nodes and to the bone marrow by means of the hematopoietic system. Tumor cells metastatic to marrow can infiltrate cortical bone. Neuroblastomas also can metastasize to the liver, most notably in patients with stage $4 \mathrm{~S}$ tumors, in whom involvement can be extensive; however, transient and complete regression often occurs with no intervention other than supportive care. 


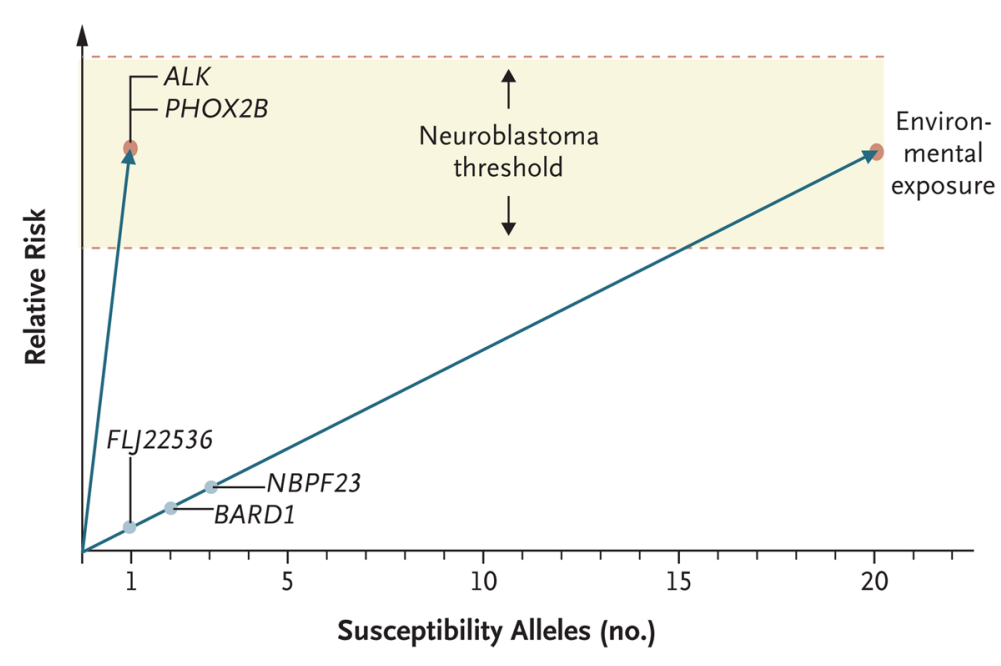

Figure 2. Model of Genetic Susceptibility to Neuroblastoma

The $\mathrm{y}$ axis indicates the theoretical relative risk of neuroblastoma, and the $\mathrm{x}$ axis indicates the number of known and theoretical susceptibility alleles. A genetic threshold for the development of disease has been postulated, and malignant transformation is probably modified by interactions related to environmental exposure. A mutation in the $A L K$ or $P H O X 2 B$ gene results in a single, highly penetrant risk allele that allows developing neuroblastic tissue to meet or exceed this threshold for malignant transformation. These types of mutations are powerful enough to permit neuroblastoma to occur within families as a mendelian trait. On the other hand, there are multiple common DNA variations (polymorphisms) in a large number of genes that cooperate to reach this threshold in patients without $A L K$ or $P H O X 2 B$ mutations. For these sporadic cases of neuroblastoma, an excessive inheritance of "risk" variants has been postulated that increases susceptibility to the disease. Discovered susceptibility genes include FLJ22536, BARD1, and NBPF23. The total number of susceptibility loci is not currently known, nor is it known whether these polymorphisms act in an additive or synergistic (epistatic) fashion. 


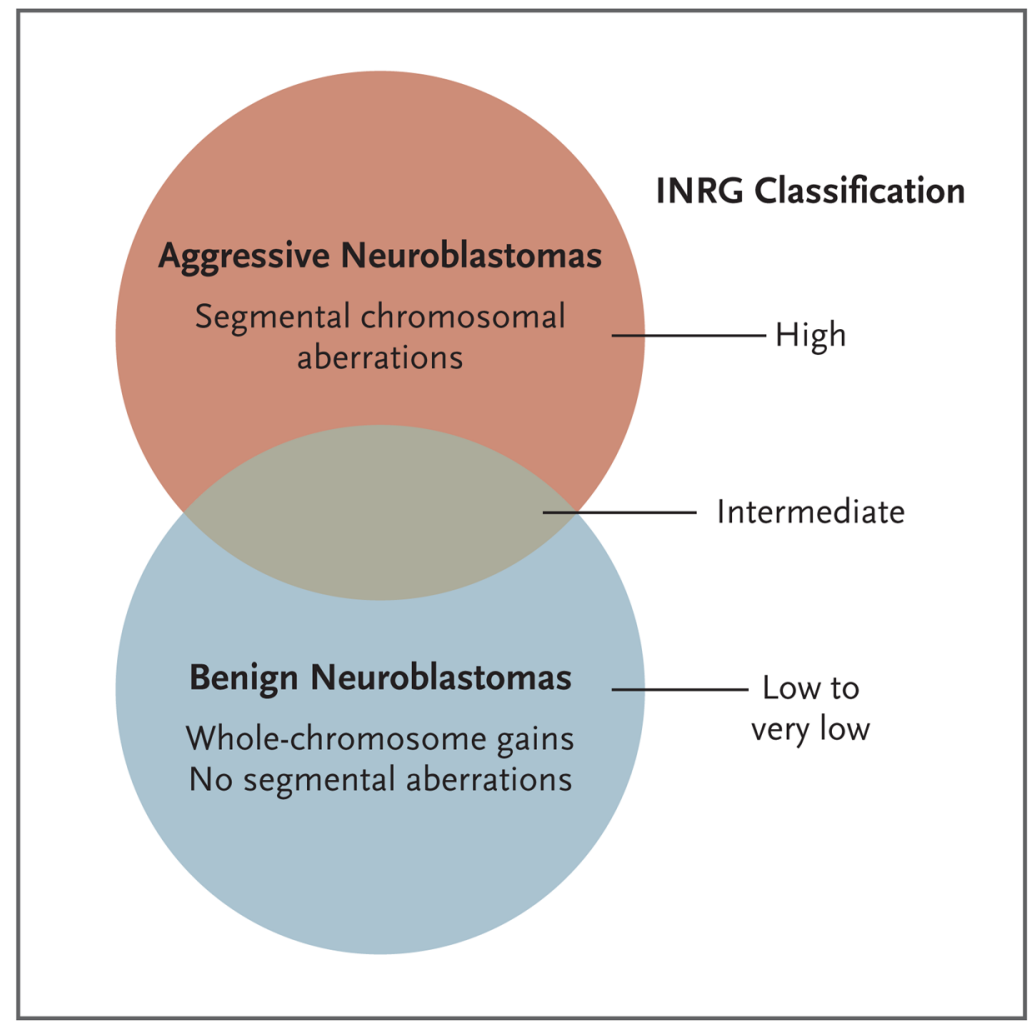

Figure 3. Genomic Basis of Neuroblastoma Risk Groups

Two broad neuroblastoma phenotypes - aggressive and benign — are seen clinically, with the latter showing a high propensity for spontaneous regression or differentiation. These two groups are largely identifiable at a chromosomal level by the presence of segmental aberrations (translocations, amplifications, and deletions) in the more aggressive cases and by whole-chromosome gains in the more benign cases. Thus, the International Neuroblastoma Risk Group (INRG) classification is related to these chromosomal alterations, but the current system is imprecise, since the intermediate group in particular remains poorly defined. Current investigation is focused on the identification of molecular predictors of outcome in the high-risk group (as well as in patients with aggressive neuroblastomas masquerading as more benign forms of the disease). 
Table 1

Phenotypic and Genetic Features of Neuroblastoma, Treatment, and Survival According to Prognostic Category

\begin{tabular}{|c|c|c|c|c|}
\hline \multirow[t]{2}{*}{ Variable } & \multicolumn{4}{|c|}{ Prognostic Category ${ }^{*}$} \\
\hline & Low Risk & Intermediate Risk & High Risk & Tumor Stage 4S \\
\hline Pattern of disease & Localized tumor & $\begin{array}{l}\text { Localized tumor with locoregional lymph- } \\
\text { node extension; metastases to bone marrow } \\
\text { and bone in infants }\end{array}$ & $\begin{array}{l}\text { Metastases to bone marrow and } \\
\text { bone (except in infants) }\end{array}$ & $\begin{array}{l}\text { Metastases to liver and } \\
\text { skin (with minimal bone } \\
\text { marrow involvement) in } \\
\text { infants }\end{array}$ \\
\hline Tumor genomics & Whole-chromosome gains & Whole-chromosome gains & Segmental chromosomal aberrations & Whole-chromosome gains \\
\hline Treatment & Surgery $^{\dagger}$ & Moderate-intensity chemotherapy; surgery ${ }^{\dagger}$ & $\begin{array}{l}\text { Dose-intensive chemotherapy, } \\
\text { surgery, and external-beam } \\
\text { radiotherapy to primary tumor and } \\
\text { resistant metastatic sites; } \\
\text { myeloablative chemotherapy with } \\
\text { autologous hematopoietic stem-cell } \\
\text { rescue; isotretinoin with anti-GD2 } \\
\text { immunotherapy }\end{array}$ & Supportive care ${ }^{f}$ \\
\hline Survival rate $(\%)$ & $>98$ & 90 to 95 & 40 to 50 & $>90$ \\
\hline
\end{tabular}

* Patients are categorized into prognostic groups according to risk, as described by the Children's Oncology Group, with the level of risk defining the likelihood of death from disease. ${ }^{7}$ Stage $4 \mathrm{~S}$ disease is considered separately here because of the unique phenotype of favorable biologic features and relentless early progression but ultimately full and complete regression of disease. ${ }^{31,32}$

${ }^{\dagger}$ The goal of surgery is to safely debulk the tumor mass and avoid damage to surrounding normal structures while also obtaining sufficient material for molecular diagnostic studies. Some localized tumors may spontaneously regress without surgery. 33

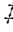
months of age, who are at much higher risk for life-threatening complications from massive hepatomegaly. 